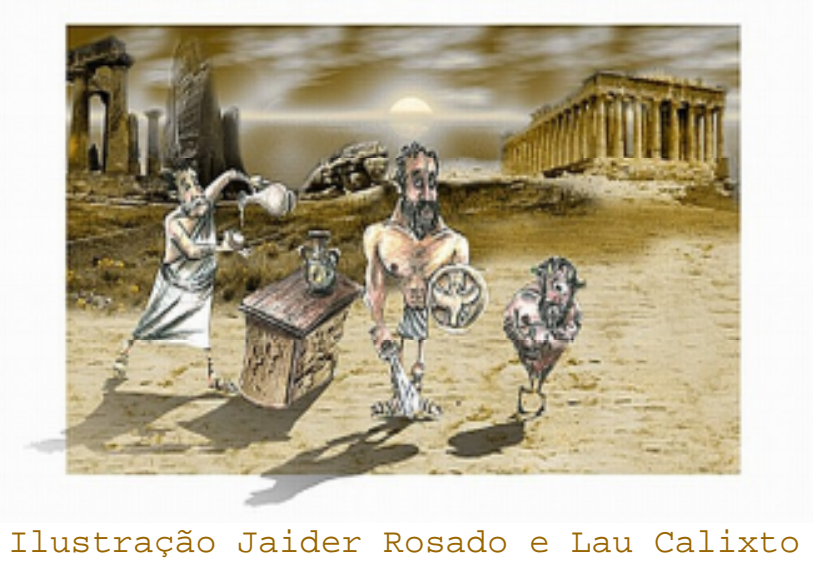

\title{
Conversando sobre Derrida
}

\author{
Evando Nascimento \\ por Luiz Fernando Ferreira Sá
}

Evando Nascimento, professor Adjunto de Teoria da Literatura da UFJF, publicou e tem publicado vários livros e ensaios sobre Jacques Derrida.

Luiz Fernando Ferreira Sá é doutor em Literatura Comparada pela faculdade de Letras da UFMG, professor de Literatura de Expressão Inglesa na Faculdade de Letras - UFMG e membro do Programa A tela e o texto.

\section{Luiz Fernando Ferreira Sá - Qual a relação que você poderia estabelecer entre Derrida e leitura ou entre leitura e desconstrução?}

Evando Nascimento - Desde os primeiros textos de Derrida, publicados na década de 1960, há uma prática e uma teoria da leitura, que são também mais do que uma simples prática ou teoria em sentido clássico. Explico. Já na abertura daquele que é provavelmente seu ensaio mais conhecido, "A Farmácia de Platão", Derrida afirma: "Um texto só é um texto se ele oculta ao primeiro olhar, ao primeiro encontro, a lei de sua composição e a regra de seu jogo" (cito a tradução de Rogério da Costa). Em seguida, ele vai dizer que essa lei e essa regra nunca se entregam de todo a uma percepção, certamente porque elas não são únicas, nem fixas. Há leis e regras que organizam textualidades em movimento, em permanente transformação. o que há quatro décadas os meios universitários e uma parte da mídia se acostumaram a chamar de "desconstrução" (termo que Derrida 
preferia utilizar no plural) foi e continua sendo, antes de mais nada, um modo de ler o texto da "metafísica ocidental". Em parte, é preciso levar em conta a constituição dos conceitos filosóficos: o modo como eles operam e como influenciam áreas que não pertencem mais estritamente à filosofia, como a psicanálise, a crítica e a história literárias, a sociologia, a etnologia, até mesmo a economia e a política. Percebe-se assim que "texto" não é mais meramente um discurso isolado, que se prestaria a uma análise exaustiva, tal como se praticava no estruturalismo. Um dos distanciamentos propostos por Derrida em relação à perspectiva estruturalista foi justamente levar em consideração os escritos e as falas submetidos à leitura, dentro de determinados contextos e analisando-se os pressupostos discursivos. É nesse sentido que procuro ler com meus alunos "A Farmácia de Platão" como uma espécie de "tratado político", ou antes, como ensaio de desconstrução das relações de poder a partir de textos filosóficos. Pois ao ler o Fedro de Platão, Derrida está lendo simultaneamente não só este como diversos outros diálogos socrático-platônicos, para ver até que ponto eles determinaram o surgimento da filosofia como discurso fundante de centramentos clássicos. Exemplificando: o rebaixamento que sócrates propõe da escrita significa um privilégio da Voz, da autoridade paterna. A escrita aparece como transgressora por poder dizer aquilo que seu pai-autor jamais diria, estando longe dele. Nesse sentido é que digo que essa teoria e essa prática não são mais em hipótese alguma mera análise estrutural, mero desmembramento de sintagmas e categoremas para se chegar a uma "estrutura geral" dos textos platônicos. A estrutura que interessa é a do poder, como privilégio da Voz, do logos e do falo: o centramento próprio ao fonofalogocentrismo.

Alguns críticos da obra de Derrida e da noção de desconstrução em Derrida alegam que a desconstrução na sua forma angloamericana nada mais é que uma leitura atenta (close reading) hiper intensificada. Como você veria essa prática de leitura "hiper-intensificada" e a proposta acima sugerida (ementa da revista txt, por exemplo) de "dessacralização" da leitura?

Essa avaliação deve ser feita levando em conta o contexto americano, suas práticas universitárias, suas necessidades institucionais, certamente diferentes das nossas, muito embora comparações possam ser legitimamente feitas. Como não conheço os detalhes dessa longa história da "deconstruction in America", prefiro evitar comentários superficiais. Apenas anotaria que, até onde posso ver, existe por lá uma diversidade de leituras, impossíveis de serem tipificadas num só padrão. Além disso, nada tenho contra as leituras atentas 
em si mesmas, pois podem ter uma grande utilidade para 0 público não-especializado. Uma leitura bem minuciosa pode ser extremamente generosa com seus leitores, depende do modo como é feita. Dito isso, acredito que a leitura deveria preferencialmente ir além do texto. Embora esse termo tenha sofrido grande desgaste nos últimos tempos, pois tem servido para tudo, creio que as leituras mais efetivas são sempre culturais. Nunca é a literatura ou a filosofia, ou qualquer outra disciplina que conta isoladamente. Ler, com efeito, é desarticular sentidos por demais sedimentados e rearticular novas possibilidades de significação. Tudo o que permite repensar as formas pré-dadas (e predatórias...) de interpretação do mundo, no sentido de descentrá-las, pode ter efeitos de desconstrução. Pois em vez de um método fixo, as desconstruções são acontecimentos que ocorrem como resultado de certo percurso de leitura, em contextos específicos, de acordo com os sujeitos envolvidos.

\section{Como você entende a noção de "desleitura" (misreading) em Derrida? Seria essa desleitura uma recusa de leitura? Se alguns textos "dizem" o oposto daquilo que parecem "dizer", não seria toda leitura simultaneamente uma desleitura?}

"Desleitura" não é uma categoria derridiana e nem tampouco eu a utilizaria como recurso de desconstrução. Derrida jamais propôs dizer o "oposto" do que um texto em si mesmo diria. Primeiro porque nunca se parte de um suposto significado único, jazendo no fundo da obra. O que existe são tradições de leitura que precisam ser avaliadas e desmobilizadas. Por exemplo, é praticamente consensual em nossa cultura que a verdadeira amizade se dá entre homens, ou pelo menos esta é a forma mais valorizada de relação amical. Esse esquema "fraterno", entre irmãos apenas, é desmontado em todas as suas peças por Derrida em Politiques de l'amitié [Políticas da amizade], no qual ele propõe reintroduzir a figura da irmã para poder propor um outro tipo de comunidade. Antígona, de Sófocles, fornece mais de um argumento para isso. Retomando também o exemplo citado do Fedro, "A Farmácia" não diz o oposto do texto platônico, mas mostra justamente as diversas camadas (algumas contraditórias entre si) de que ele é composto. Cada camada ou fio do texto, em sua extrema complexidade, torna de fato inviável dizer que o texto diz uma única coisa ou afirma uma tese sem contradições. Esse "querer dizer" monolítico, quando se manifesta, já seria um dos mitos do platonismo. É isso que a leitura desconstrutora busca: desestruturar mitologias culturais demasiadamente consolidadas, tais como a da consciência plena, de uma racionalidade absolutamente consciente e onipotente, de uma hegemonia da força viril. 


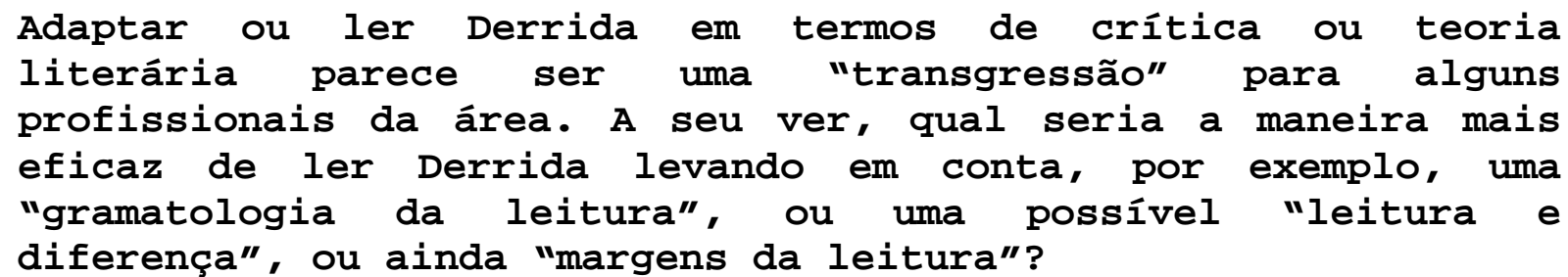

As leituras mais efetivas, a meu ver, são sempre diferenciais, quer estejam ligadas ao que se nomeia como desconstrução, quer não. Elas devem de algum modo estar vinculadas à singularidade do sujeito que lê. A história pessoal do sujeito ou dos sujeitos leitores é decisiva para as possibilidades de intervenção crítica no mundo. O melhor exemplo disso é o próprio Derrida: se ele pode ler textos da tradição filosófica, quer dizer originalmente européia, de um modo inovador, isso certamente se deve a suas origens na Argélia, um país de colonização francesa até meados do século XX. Seus trabalhos trazem essa marca de judeu argelino que, infelizmente para ele, não falava o árabe mas somente 0 francês, o qual, como diz em Le Monolinguisme de l'autre [0 Monolinguismo do outro], não era "seu" idioma. Pergunto: alguém tem a posse jamais de um idioma? Ou o idioma é simplesmente aquilo que nos atravessa e até certo ponto nos faz falar? Então, para mim, Derrida é esse imigrante naturalizado francês que nunca teve outra cultura senão a Ocidental, à qual ele nunca pertenceu de todo... Percebe a ambigüidade? É um lugar descentrado, de quem conhece a fundo o pensamento ocidental mas que desde sempre se situou às suas margens, Lembro que Margens - da Filosofia é um de seus primeiros livros, publicado em 1972. E sua leitura de textos canônicos se faz muitas vezes a partir de textos menos lidos de pensadores conhecidos, como era o caso do ensaio sobre a Origem das línguas, de Rousseau, nos anos 1960, desconstruído na Gramatologia. Cabe a nós, leitores de Derrida, num país sul-americano, descobrir nosso modo de ler (com) ele os textos de nossa cultura, a qual também participa mas não pertence de todo à cultura ocidental. Basta conversar com qualquer scholar europeu ou mesmo norte-americano para ele pôr em dúvida nossa ocidentalidade. Esta lhes parece mais uma "acidentalidade" (em sentido negativo), para retomar um jogo de palavras famoso de Lacan. No fundo, acho que qualquer participação numa cultura, ocidental ou não, é sempre um "acidente", algo que vem como por acaso e que pode ser direcionado em múltiplos sentidos. Os rumos da participação cultural dependem eminentemente dos sujeitos históricos. Assim, precisamos apenas reverter essa "falta de cultura" plenamente ocidentalizada num benefício. Transformar a "falta" numa força, pois o fato de não pertencer de todo à visão hegemônica do Ocidente pode ser um bem, depende somente de que encaminhamento se dê a isso. Leitura para mim é, portanto, qualquer intervenção refletida e desconstrutora no espaço da cultura. Pode ser um ensaio 
acadêmico, uma intervenção em sala de aula ou em congresso, ou mesmo um artigo de jornal, uma entrevista, um debate público. Tudo depende de como se lê, desmontando quais pressupostos, deslocando quais centramentos, reavaliando quais valores, e assim por diante.

Para muitos Ler o texto é necessariamente Ler o mundo. De que maneira poderíamos pensar a noção de "disseminação" em Derrida e essas possíveis "leituras de mundos"?

Ler é certamente ler o mundo, o problema é que os limites do mundo conhecido andam cada vez mais fluidos. Recentemente li que, enfim, a sonda Voyager ultrapassou os limites do sistema solar. Parece que o sonho de colonizar o mundo se deslocou em definitivo para o espaço sideral, e lá não faltam terras nãodescobertas (undiscovered countries, parafraseando Hamlet). Ler o mundo seria tentar entender justamente essa "pulsão colonizadora" que não é exclusiva do Ocidente, pois países de outras regiões também praticaram formas cruéis de imperialismo, mas na era moderna isso tem sido a marca da Europa e, mais recentemente, dos Estados Unidos da América. Não devíamos talvez esquecer que nós vivemos também nos Estados Unidos... do Brasil. E se o mapa da América fosse invertido, tal como propôs o artista Torres-Garcia, quem sabe nós é que fôssemos ricos... o poderio americano é esplendidamente desconstruído por Jean-Luc Godard no filme excepcional que é O Elogio do amor. Eis aí um belo exemplo de desconstrução fora da universidade, mas que deveria ser didaticamente projetado e discutido em sala de aula, em todas as escolas. Eu diria sobre Godard o mesmo que Derrida disse sobre Beckett: em seus filmes-textos nada mais há a desconstruir, o serviço até certo ponto já foi feito. Cabe ao leitor-espectador re-instrumentalizar essa leitura desconstrutora que um pensador-cineasta como Godard propõe. 0 mesmo eu diria do mais recente Nossa música, sobre Sarajevo pós-guerra. São filmes que infelizmente nunca passam na TV aberta e que dão tanto a pensar. Obras políticas para sociedades despolitizadas ou, pelo menos, desmobilizadas. Há que se colocar a política dos cidadãos na ordem do dia, porque a política dos políticos, no Brasil e no mundo, se corrompeu de vez.

Cito: "Although Derrida had long before his death become passé in academic literature departments, what he has to offer to the appreciation of 'that writing which is called literary' has barely begun to be understood". Primeiro: seria a leitura de textos de Derrida uma tarefa hercúlea? Segundo: seria a 
leitura uma mera apreciação de texto e como apreciar o texto literário via uma leitura derridiana? Terceiro: como se ensina - prazer da leitura, seja ela a leitura de Derrida ou a leitura daquilo que costumamos chamar "literário"?

Respondendo a primeira indagação: não em absoluto, não é uma tarefa hercúlea ler um texto individual ou o conjunto dos textos de Derrida. O que importa de fato é o modo como se realiza a leitura e como se a instrumentaliza em relação aos espaços institucionais em que se atua (universidade, cinema, teatro, política e outras áreas). Importa a capacidade de cada um de articular essas leituras a outras que não se dão necessariamente "sobre" ou a partir de textos de Derrida. Quem somente lê Derrida acaba por não compreender nem Derrida... De minha parte, leio não somente seus textos, mas muitas de suas referências, bem como diversos outros teóricos e críticos próximos ou distantes de Derrida, como Foucault, Barthes, Deleuze, Lyotard, Benjamin, Adorno, Haroldo de Campos, Julia Kristeva, dentre vários outros, brasileiros e estrangeiros. A lista por definição não tem fim. Quanto à segunda indagação: a primeira parte já foi respondida anteriormente.

Sobre a outra parte, acho importante perceber que Derrida, ao contrário de Sartre e mesmo de Merleau-Ponty, não usa o texto literário ou o texto artístico (os desenhos de Antonin Artaud, por exemplo) como mera ilustração de teses filosóficas. Ao contrário, o texto literário é que propõe uma forma de pensamento que a filosofia jamais proporia. O exemplo que me ocorre de imediato é "La Loi du genre" [A Lei do gênero], um ensaio incluído em Parages, que é um livro inteiro dedicado a Maurice Blanchot. Pois bem, neste ensaio Derrida repensa todo - aparato classificatório próprio à filosofia, à teoria e à crítica literárias, e até mesmo à biologia, no que diz respeito à questão do gênero. E ele faz isso recorrendo a uma brilhante narrativa de Blanchot intitulada La Folie du jour [A Loucura do dia]. É a "loucura" desse texto literário que trava - mecanismo das classificações, pois desde logo ele emperra a possibilidade de se fazer um relato com começo-meio-e-fim. A narrativa é sobre a impossibilidade de narrar, de prestar testemunho diante das autoridades competentes. Inclusive a própria oposição entre os gêneros sexuais (o que no mundo anglo-saxão se nomeia como gender) se vê problematizada pelo suposto narrador, que se sente obrigado a falar de outro modo dos papéis sexuais. Assim, em vez de discutir teoricamente a questão do gênero (discursivo, sexual, ontológico etc.) Derrida põe o texto de Blanchot para falar, e a literatura dificilmente fala com a mesma sintaxe e o mesmo vocabulário da filosofia... Claro que o aproveitamento dessas estratégias depende muito de cada leitor, que pode ou não se dar conta do que se passa entre o texto de Blanchot e o de Derrida. E o que pode se passar também no texto dele, leitor. Repito: leitura é 
acontecimento, que pode ou não vir, ter lugar, acontecer. Nada garante de antemão que "minha" leitura vá ter êxito, tudo depende do modo e do contexto de sua recepção. O sucesso, ou não, de minha maneira de ler vai muito além de mim. Quanto à terceira indagação: creio que o prazer não se ensina. A propósito de qualquer texto, o professor pode preparar seus alunos para uma intervenção mais efetiva em relação aos textos que lê, de Derrida ou de literatura em geral. Mas um modo de possibilitar esse prazer, como o faço em minha prática com os alunos, é ajudá-los a percorrer caminhos não usuais de descoberta dos textos. E também ajudá-los a ver que um texto não nasce solto no espaço, que ele certamente já vem como "resposta" a outros que o precedem, assim como escavam o espaço de novas leituras-escrituras. Há uma correspondência ininterrupta entre os textos, correspondência tanto sentido de ligações entre eles, quanto no de mensagens que eles se remetem uns aos outros: leituras, desdobramentos, transformações. Creio, como Barthes leitor de Nietzsche, que a leitura se efetiva enquanto produção e não como mero consumo. $E$ É quando me disponho a falar e/ou escrever a partir de um texto, de preferência de modo não impositivo, que o gozo verdadeiro da leitura se faz. E o gozo da leitura é uma forma de transgredir a leitura burocrática, feita apenas para cumprir tarefa. Os melhores leitores são sempre inventivos. O pensador que mais me ajudou a perceber isso foi com certeza Nietzsche, aquele que recusava terminantemente toda passividade ou "reatividade" diante da filosofia, da literatura e do mundo. O papel do leitor precisa ser ativo, imaginativo, desdobrando 0 que 0 texto do outro não pôde dizer. Texto algum jamais disse tudo, sobre qualquer assunto. É por isso que a leitura nunca se esgota: não porque haja sempre "mais sentido" no fundo do texto - eu diria quase o contrário, é porque o texto do outro deixou de dizer muita coisa que posso retomá-lo e ir adiante, me aventurando por outros caminhos. Gosto de brincar com os alunos declarando que nada ainda foi dito, tudo resta por dizer. Para mim, isso é uma felicidade, sem a qual o pensamento morreria. Será por acaso que alguém escreve cerca de 80 livros? E Derrida escreveria muito mais se chegasse aos cem anos... Sempre teria algo a dizer que nem ele nem ninguém disse ainda.

Cito: "...a literatura nunca é apenas literatura; o que lemos como literatura é sempre mais - é História, Psicologia, Sociologia. Há sempre mais que literatura na literatura. No entanto, esses elementos ou níveis de representação da realidade são dados na literatura pela literatura, pela eficácia da linguagem literária. Então, entre esses níveis de representação da realidade e sua textualização, seu aparecimento enquanto literatura, há um intervalo - mas é um 
intervalo (...) muito pequeno ..." (João Alexandre Barbosa). Derrida nos ajudaria, nós leitores, a ler esse "sempre mais" que há na literatura? Levando em conta que ajudar não é necessariamente facilitar, poderia Derrida nos ajudar a ler o intervalo em vez de cair nele (mesmo que intervalo e mesmo que muito pequeno)?

O intervalo para mim é um bem, é a falha entre mim e o texto do outro que me permite falar. Só posso falar porque há buracos, fendas, até mesmo rachaduras... Ali onde há plenitude de sentido, nada mais se pode dizer ou escrever, pois o pensamento trava. É isso que é cansativo numa grande parte do discurso da mídia (não toda, é claro): fala-se, repetem-se as mesmas coisas até à náusea, como um saber pronto a ser consumido pelo espectador. Excesso de significado préfabricado acaba sendo esmagador. Mas até nesses casos pode-se começar a desfazer essa plenitude que Derrida chamou de "artefatualidade": a atualidade como um artefato pré-moldado pelo discurso da mídia. Cabe assumir um outro ritmo, o tempo da reflexão. Ouvir a mídia, televisiva ou não, mas saber interrompê-la para escutar aquilo que ela não diz explicitamente, suas falhas e rombos. Um bom exercício de sala de aula seria pegar um trecho de um telejornal qualquer e desmontar as diversas peças, tanto discursivas quanto técnicas, pois as duas se relacionam intimamente. Em seguida, relacionar com textos literários que tratam do mesmo assunto porém com uma abordagem crítica, efetivamente desconstrutora. Essa seria uma excelente atividade de "literatura comparada" no contexto atual. Não diria jamais que a literatura representa a realidade ou a sociedade. Ela dialoga, intervém, recorta, reelabora o discurso do entorno. Representar suporia uma relação sujeito-objeto que considero uma concepção limitadora, até mesmo ultrapassada hoje. Todo discurso é ao mesmo tempo sujeito e objeto, assunto e discurso, matéria e forma. A literatura para mim não representa nada, mas sim propõe modos de se pensar o mundo a partir de um detalhe, que muitas vezes a mídia ignora. O que amo na literatura é o detalhe, o ponto irrelevante que demonstra todo um universo, ajudando a desmontar suas forças hegemônicas. Freud também amava os detalhes, com isso pôde elaborar uma teoria de grande potência desconstrutora, embora também ainda vinculada a centramentos tradicionais. Igualmente, a ficção de clarice Lispector dispõe de inúmeros detalhes assim, surpreendentes, desconstrutores. Deixo aqui a lacuna para o leitor preencher com seu próprio exemplo, com seu detalhe particular, vindo de Clarice ou não. 